\title{
Residence time of the Danshuei River estuary, Taiwan
}

\author{
Chi-Fang Wang, Ming-Hsi Hsu, Albert Y. Kuo* \\ Department of Bioenvironmental Systems Engineering, National Taiwan University, Taipei 106, Taiwan
}

Received 27 October 2003; accepted 28 January 2004

\begin{abstract}
The residence time of an estuary is defined in this study as the average time the initially existing water parcels reside in the system before they are flushed out. The residence time of the Danshuei River is calculated through a series of numerical experiments using a laterally integrated two-dimensional hydrodynamic eutrophication model (HEM-2D). The results show that the residence time is on the order of 1-2 days under the mean river flow to zero river flow condition, which is very short compared with most time scales of biogeochemical processes. A procedure is developed to quantify individual contribution to flushing by each of the three major physical transport mechanisms: tide, river discharge, and the density induced circulation. The results indicated that, in general conditions, tidal flushing exerts the greatest influence to the flushing of the Danshuei River estuary, while the density induced circulation hardly contributes any. Tidal transport contributes more than $50 \%$ of the flushing when river discharge is below its longterm mean. The suitability of applying the tidal prism method, the modified tidal prism methods, and the fraction of freshwater method in this estuary is also investigated. The relatively short residence time is likely to be one of the limiting factors that result in low phytoplankton biomass in spite of extremely high nutrient concentrations, and causes a significant fraction of pollutants to exert their effects in the coastal waters outside the estuary.
\end{abstract}

(c) 2004 Elsevier Ltd. All rights reserved.

Keywords: residence time; physical transport; numerical modeling; Danshuei River

\section{Introduction}

In general term, the residence time of an estuary is the average time a dissolved or suspended matter resides in the estuary before it is carried out into the open sea. The residence time is a convenient parameter representing the time scale of physical transport processes, and often used for comparison with time scales of biogeochemical processes. It has an important implication to the fates of introduced substances, and the primary productivity in the estuaries. A pollutant will exert most of its effects within an estuary if its biochemical time scales are comparable to, or shorter than the residence time. Primary production by the free flowing phytoplankton will be low if the time scale for their net growth is much longer than the residence time. The month-long residence time was ascribed to be the cause of the eutrophication and hypoxia/anoxia in the Chesapeake Bay for most of the

\footnotetext{
* Corresponding author.

E-mail address: akuo@hy.ntu.edu.tw (A.Y. Kuo).
}

anthropogenic nutrients discharged into the system exert their effects within it (Cerco and Cole, 1993). The reported increase of primary production rate in the Hudson River as the river flow decreased was also attributed to the increased residence time (Howarth et al., 2000). In a reviewing paper, Jay et al. (1997) used residence time as an independent variable while discussing biogeochemical processes in estuaries. Dettmann (2001) used residence time and a first-order biogeochemical rate coefficient to formulate a simple two-parameter model to illustrate the relative contribution of the physical transport and biogeochemical processes in estuaries. He applied the model to calculate the annual average fraction of total nitrogen input from land that is exported and related it to residence time for 11 North American and European estuaries.

The Danshuei River estuary is the largest tidal river and one of the most heavily polluted rivers in Taiwan, consisting of three major tributaries: the Tahan Stream, Hsintien Stream and Keelung River (Fig. 1). The mean tidal range is $2.17 \mathrm{~m}$ at river mouth with the $\mathrm{M}_{2}$ tide as the principal tidal constituent. The median river 


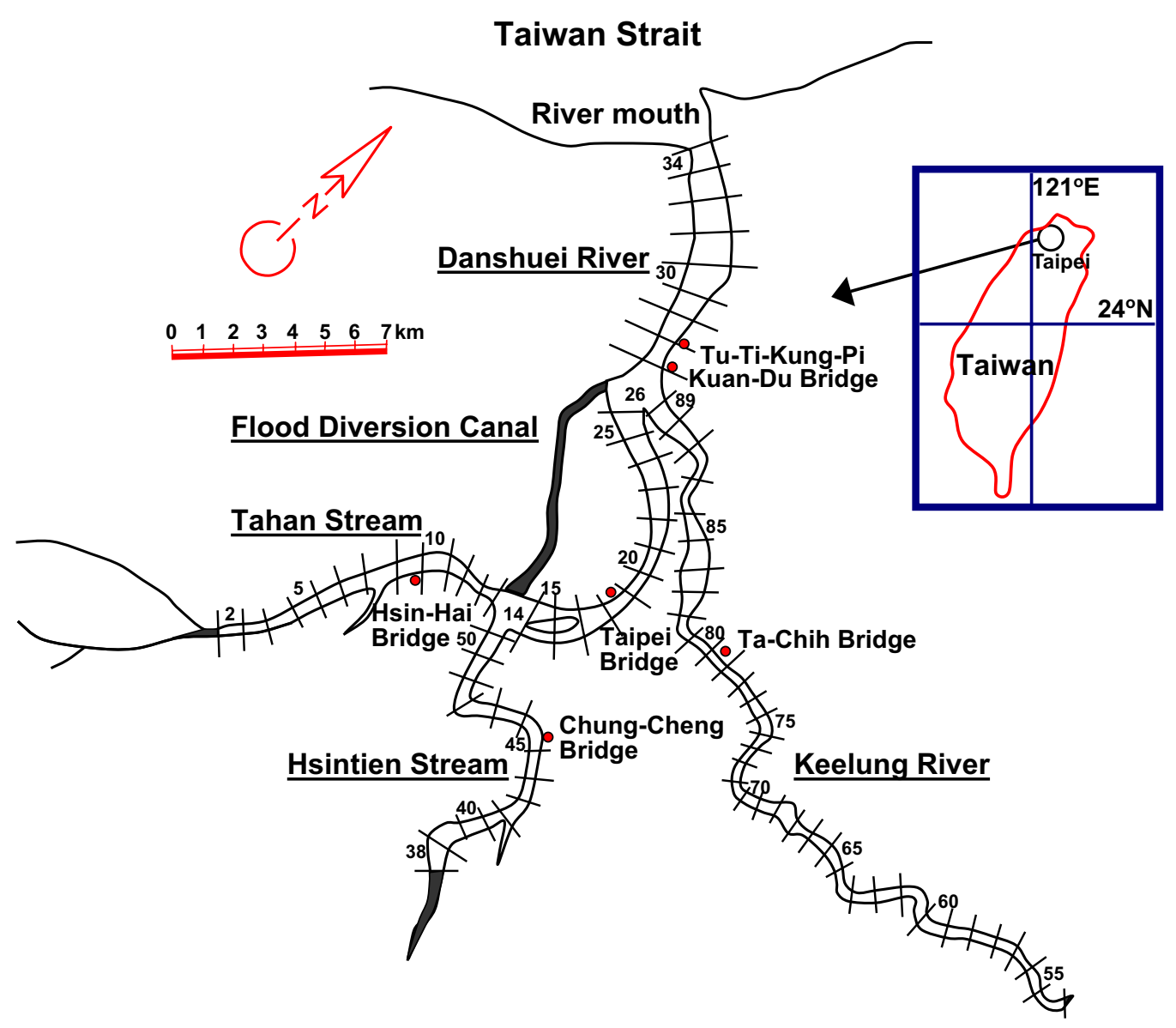

Fig. 1. Map of the Danshuei River estuary and the model segments.

discharges at the upstream limits of tides are 12.8, 23.7 and $9.8 \mathrm{~m}^{3} \mathrm{~s}^{-1}$ in Tahan Stream, Hsintien Stream and Keelung River, respectively. There are six million people living in the river basin, which includes the capital city of Taipei. Untreated, as well as treated domestic sewage and industrial effluents have made the river heavily polluted. The upper estuary is normally hypoxic/anoxic, and gradually becomes hypoxic/normoxic in the lower estuary with increasing dilution by seawater (Chen and Hung, 1988). The nutrient concentrations are extremely high while the plankton biomasses are very low. A monitoring program of Taiwan Environmental Protection Agency reported that inorganic nitrogen and phosphorus concentrations were observed on the order of $5 \mathrm{~g} \mathrm{~m}^{-3}$ and $0.5 \mathrm{~g} \mathrm{~m}^{-3}$, respectively, throughout the estuarine proper, and in all seasons. A group of researchers at the Taiwan's Academia Sinica conducted a three-year (1999-2001) monitoring program of the ecological conditions in the estuarine proper. They rarely observed a chlorophyll $a$ concentration above $5 \mathrm{mg} \mathrm{m}^{-3}$. Primary production rate was estimated on the order of $0.1 \mathrm{~g} \mathrm{C} \mathrm{m}^{-2} \mathrm{~d}^{-1}$ and zooplankton biomass was observed to be on the order of a few $\mathrm{mg} \mathrm{C} \mathrm{m}^{-3}$.

With the high nutrient concentrations and low zooplankton biomass, neither the nutrients nor the grazing could be the limiting factor for the primary production in this estuary. Chen et al. (2003) studied the water column light attenuation and reported the attenuation coefficient on the average of $2.0 \mathrm{~m}^{-1}$ in the lower estuary. This gives a photic depth of $2.3 \mathrm{~m}$, about $50 \%$ of the average water depth and makes the light an unlikely limiting factor for primary production. The remaining potential limiting factors are residence time and toxic effects of polluted waters.

There are three objectives in this study: first, to investigate the residence time of the Danshuei River estuary in order to examine if it is the cause of low primary productivity; second, to quantify the contribution to the flushing ability by each of the three major physical transport mechanisms: tide, river discharge, and the density induced circulation; and third, to examine the suitability of applying some widely used methods to estimate the transport time scales in this estuary. In the following, several methods for estimating transport time scales are discussed. The residence time of the Danshuei River estuary is then calculated by the aids of a numerical model. Individual contribution by each of the three major transport processes is quantified. Finally, discussions and conclusions are made according to the results. An appendix is also given summarizing the 
definitions and calculation methods for the commonly used physical transport time scales.

\section{Methods for calculating residence time}

The residence time of an estuary, or segment of it, is often loosely referred to as the average time a water parcel or introduced substance remains within the system, or area of interest. The time period a water parcel, or substance, remains within a system depends on the location and time the water parcel is "tagged" or the substance is introduced (van de Kreeke, 1983; Prandle, 1984). Therefore a more precise definition should be made depending on the utility of the term. A definition applicable to a system of water body, or segment of it, is the average time for all the existing water remains within the system. If all the existing water parcels in a water body, or segment of it, are "tagged" at some instant of time, inevitably some of them will be flushed out of the system quickly while some may stay for a longer period of time. In this paper the residence time of the system is proposed to be defined as the average time these initially existing water parcels reside in the system before they are flushed out. This is a single parameter representing the integral time scale of all physical transport processes in the system combined, which may be used to compare with the time scales of biological and chemical processes. Zimmerman (1988) also defined several local time scales which are functions of location in estuaries. The local time scales provide more detailed information, however they suffer from complication while relating to biogeochemical processes. Therefore the discussion in this paper will be confined to the integral time scale which represents the average values of the whole or segment of an estuary.

In addition to residence time, there are several other terms used in literatures to represent the time scale of physical transport in estuaries (see Appendix A). They are the flushing time, renewal time, detention time, turnover time, exchange time, transit time, age and half life, etc. These parameters are all closely related and some may be equivalent depending on their definitions and conditions of the water bodies. Bolin and Rodhe (1973) reviewed the concepts of age and transit time distributions, and presented a theoretical basis to relate average age, turn-over time and average transit time (or residence time). Among all these time scales, the flushing time is the one most commonly used since all of them are determined by the ability an estuary can flush its existing water out to the open sea. It is obvious that the residence time of an estuary will increase or decrease with its flushing time. The longer it takes to flush an estuary, the longer its residence time will be. The flushing of estuarine waters is achieved by all the mechanisms effecting the transport or removal of water from the estuary to the open sea. These transport mechanisms include tidal flushing, river discharge, density induced estuarine circulation and those induced by meteorological events and topographic configurations. The ability of these mechanisms to transport or to renew the estuarine waters determines the transport time scale. The flushing ability may be defined as the flushing rate of the estuary, which is of the dimension of time ${ }^{-1}$. For instance, a flushing rate of 0.1 day $^{-1}$ means that onetenth of its water is removed every day and its flushing time is 10 days. The flushing abilities, or flushing rates, attributable to various mechanisms acting simultaneously may be cumulative; however, the flushing time and residence time are not.

Several textbooks (e.g., Bowden, 1967; Dyer, 1973, 2000; Officer, 1976; Fischer et al., 1979) defined the flushing time of an estuary as "the time required to replace the existing freshwater in the estuary at a rate equal to the river discharge". Another definition of flushing time is the time required to replace all existing water in an estuary at a rate equal to the equivalent outflow (Officer, 1976; Knauss, 1978), or the available new waters (Pritchard, 1960). There is no theoretical basis that the two should be the same. Both definitions of flushing time are based on the displacement concept which gives the time required to displace freshwater or all the water in the estuary once. If the river flow is constant and the water displacement is a linear process, the average time the initially tagged water remains in the system, the residence time defined in this paper, would be half of the flushing time aforementioned. In reality, there is always some degree of mixing within an estuary that the water displacement does not necessarily follow the linear process. The new water coming into the estuary, be it by river discharge, tide or non-tidal circulation, will at least partially mix with those already in the system before displacing some of them. It will take infinitely long time to replace all of the existing water in the system.

Dyer (1973) and Officer (1976) presented several methods to calculate flushing time: tidal prism method, fraction of freshwater method, water and salt budget method, and modified tidal prism method. The tidal prism method is simple and easy to apply. It simply divides the high tide volume of an estuary, or segment of it, by its tidal prism $P$, to arrive at the flushing time $T_{\mathrm{f}}$ :

$T_{\mathrm{f}}=\frac{(V+P) T}{P}$

where $V$ is the low tide volume and $T$ is tidal period. It has been found that this method grossly underestimates the flushing time because of its basic assumptions. A number of modifications to the tidal prism method have been proposed. Both Sanford et al. (1992) and Luketina (1998) incorporated a return flow factor to account for 
the incomplete flushing of tidal prism, and also modified the model to include the flushing by river discharge. Ketchum (1951), Dyer and Taylor (1973), Wood (1979), and Kuo and Neilson (1988) proposed various types of modified tidal prism model to account for the incomplete mixing in an estuary by dividing it into segments of length of tidal excursion. They also incorporated river discharge and return flow factor.

The fraction of freshwater method calculates the flushing time as:

$$
T_{\mathrm{f}}=\frac{f V}{R}
$$

In the above equation, $R$ is the river discharge and $f$ is the mean fractional freshwater concentration in the estuary, given by:

$f=\frac{1}{V} \int \frac{S_{0}-S}{S_{0}} \mathrm{~d} v$

where $S_{0}$ and $S$ are the sea water salinity and the salinity in the estuary, respectively, and the integral is taken over the entire volume of the estuary.

The water and salt budget method calculates the flushing time by dividing the volume of the estuary with the rate of equivalent outflow through its mouth:

$T_{\mathrm{f}}=\frac{V}{Q_{0}}$

$Q_{0}$ is the equivalent estuarine outflow (or pseudooutflow, a term used by Pritchard). It may be calculated with the Knudsen's hydrographic theorem:

$Q_{0}=\frac{S_{0}}{S_{0}-S_{\mathrm{e}}} R$

where $S_{\mathrm{e}}$ is the volume-weighted average salinity of the outgoing flow during ebb tide (Pritchard, 1960), or the upper layer salinity in case there is a two-layered tidally averaged circulation at the mouth (Pritchard, 1969).

The residence time seems to be the converse of flushing time literally that the former is the time the substances stay within the system while the latter is the time required to flush the substances out of the system. In fact, they both represent the physical transport time scale even though they are from opposite point of view. Monsen et al. (2002) examined the underlying assumptions associated with flushing time, age and residence time. They described various procedures for computing them in idealized cases, and identifying pitfalls when real-world systems deviated from these idealizations. They also applied the time scale definitions to a shallow tidal lake to illustrate how deviations between real water bodies and the idealized cases can result. Sheldon and Alber (2002) also pointed out the difference in flushing and residence times of an estuary. They used various types of box models to compute the freshwater residence times of an estuary in Georgia, USA and compared them with flushing times computed with fraction of freshwater method. They found that the two methods yielded similar results if the box model segmentation length was selected properly, and that the variation of residence time may be approximated with a negative power function of freshwater discharge rate.

The residence time is preferred in this study for the major objective here is to investigate the possibility of physical transport mechanisms to be the cause of low primary productivity in this estuary. According to the definition of the residence time defined in this paper, it may be evaluated with a tracer experiment. A passive conservative tracer is introduced into an estuary, or segment of it, uniformly at some instant of time, ideally at high tide or at the tidal phase when the estuarine volume is maximal. The tracer concentration distributions are measured subsequently at the same phase of tide until most of the tracer is flushed out. The data may be used to calculate:

$M(t)=\int c(t) \mathrm{d} v$

and

$T_{\mathrm{r}}=\frac{1}{M(0)} \int_{0}^{\infty} t\left[-\frac{\mathrm{d} M(t)}{\mathrm{d} t}\right] \mathrm{d} t$

where $t$ is time, $M$ is the total mass of the tracer remains in the estuary, $c$ is the tracer concentration, and $T_{\mathrm{r}}$ is the residence time. In reality it is not always practical to conduct such a tracer experiment in prototype estuaries. Numerical experiment with a calibrated and verified numerical model may be resorted to (e.g., Edinger et al., 1998; Gillibrand, 2001; Kim et al., 2002; Rasmussen and Josefson, 2002).

In Eqs. (1), (2), and (4), if the water available to flush the estuary mixes completely with the existing estuarine water in each tidal cycle, the removal of $M(t)$ will follow a linear process and is described as:

$\frac{\mathrm{d} M(t)}{\mathrm{d} t}=-\gamma M(t)$

and

$M(t)=M(0) \exp (-\gamma t)$

where $\gamma=T_{\mathrm{f}}^{-1}$, the flushing rate. In this case the flushing time is the e-folding time, i.e., the time required to reduce the total mass of the tracer in the estuary, or segment of it, to a factor of $\mathrm{e}^{-1}$ of its original value. This time scale has been termed residence time (e.g., Knauss, 1978; van de Kreeke, 1983), and also called the turn-over time (Prandle, 1984). Substituting Eqs. (8) and (9) into Eq. (7), it may be shown that the flushing time is equivalent to the 
residence time defined in this paper. If the mixing of the incoming and existing waters in the estuary is not completed in each tidal cycle, the flushing time will not equal the residence time as defined in this paper. Eq. (7) should be used to calculate the residence time.

\section{Model description and calibration/verification}

The laterally integrated two-dimensional hydrodynamic eutrophication model (HEM-2D) developed by Park et al. (1996) was expanded to include the simulation of tributaries in the Danshuei River system (Hsu et al., 1999). This model has been used in investigating the characteristics of hydrodynamics in the Danshuei River system, such as the tidal propagation, estuarine circulation, and the salinity structure (Liu et al., 2001a,b,c).

The hydrodynamic portion of the model is based on the principles of conservation of volume, momentum, and conservative substance (such as salt). The governing equations are solved for the surface elevations and flow fields using finite difference method with rectangular grids of spatially staggered variables. In the application to the Danshuei River system, the Danshuei River and Tahan Stream are treated as the main channel, and Hsintien Stream and Keelung River as the tributaries. The modeling domain is extended to the river segments upstream of the tidal limits in all three tributaries. A uniform segment length of $1 \mathrm{~km}$ is used, in this manner the river channels are divided into 33, 14 and 37 segments, respectively. The vertical thickness of all layers is $1 \mathrm{~m}$, except the surface layer, which is variable responding to surface fluctuation, with $2 \mathrm{~m}$ at mean sea level. Hsu et al. (1999) have calibrated and verified the hydrodynamic model in the application to the Danshuei River system with the field survey data of 1994 and 1995. Details of model description and the calibration/ verification to the Danshuei River system may be found in Hsu et al. (1996, 1997, 1999).

The geometry of the river channel has changed significantly since 1995 that the geometric input for the numerical simulations in this study is updated with field data measured in 2000 . The model is then re-calibrated with the mean tide simulation, and verified with a oneyear real-time simulation. Because the $\mathrm{M}_{2}$ tide is the dominant tidal constituent at the Danshuei River mouth, a single constituent tide with the period of $\mathrm{M}_{2}$ tide is used for the mean tide simulation. The downstream boundary condition is an $\mathbf{M}_{2}$ tide with the amplitude being half of the mean tidal range, $108 \mathrm{~cm}$, and the mean surface level of $12.4 \mathrm{~cm}$, both measured in 2000. River discharges at the upstream boundaries are specified 59.2, 87.1 and $32.8 \mathrm{~m}^{3} \mathrm{~s}^{-1}$ in the Tahan Stream, Hsintien Stream and Keelung River, respectively, which are the means of the daily values in 2000 . The values of Manning friction coefficient are adjusted slightly to match the simulated tidal ranges with those calculated from field data with harmonic analysis. Fig. 2 compares the calculated mean tidal ranges with the observed values at various tide gauge stations. The absolute and relative differences between the simulated and measured tidal ranges are from 0.4 to $4.9 \mathrm{~cm}$ and from 0.2 to $2.3 \%$, respectively.

In the one-year real-time simulation, the daily river discharges measured at the upstream boundaries and the hourly surface elevation at river mouth are specified to force the model from January 1 to December 31, 2000. The time series data of longitudinal velocities measured at Kuan-Du Bridge (Danshuei River), Taipei Bridge (Danshuei River), Hsin-Hai Bridge (Tahan Stream), Chung-Cheng Bridge (Hsintien Stream) and Ta-Chih Bridge (Keelung River) on May 5, 2000 are compared with the simulated results. Fig. 3 presents an example comparing the time series data of the simulated and measured longitudinal velocities. The intra-tidal variations of the velocity on that day are well simulated with minor deviation from observation. The root mean square differences between the observed and simulated values at the five stations range from 1.14 to $5.52 \mathrm{~cm} \mathrm{~s}^{-1}$.

Because of the lack of observed salinity data in 2000, no re-calibration of the constants in turbulence model is conducted. The values obtained by Hsu et al. (1999) are retained.

\section{Model applications}

The river channels of the three major tributaries are shallow and narrow compared to the Danshuei River proper. Tidal energy diminishes gradually toward the three tributaries that they are mainly governed by freshwater flow. Being the conduit between upstream rivers and the adjacent sea, residence time of the Danshuei River proper is more relevant to the aquatic ecosystem than that of the whole river system or the tributaries. In the following, the HEM-2D model is applied to investigate the residence time of the Danshuei River only, not the entire tidal system. When applying the model to a particular scenario for a specific region of interest, all river segments within the region are specified with uniform concentration of a passive conservative tracer at some instant when the volume of the region is maximal, with all other segments being of zero concentration. The model is then run for several months of simulation time. As time proceeds, the tracer is gradually lost through the river mouth under the influence of specified physical forcing functions. The spatial distribution of tracer remaining in the estuary is used to calculate the total residual tracer mass at the corresponding time using Eq. (6). After the temporal variation of total residual mass is obtained, the residence time is calculated thereupon based on Eq. (7). 

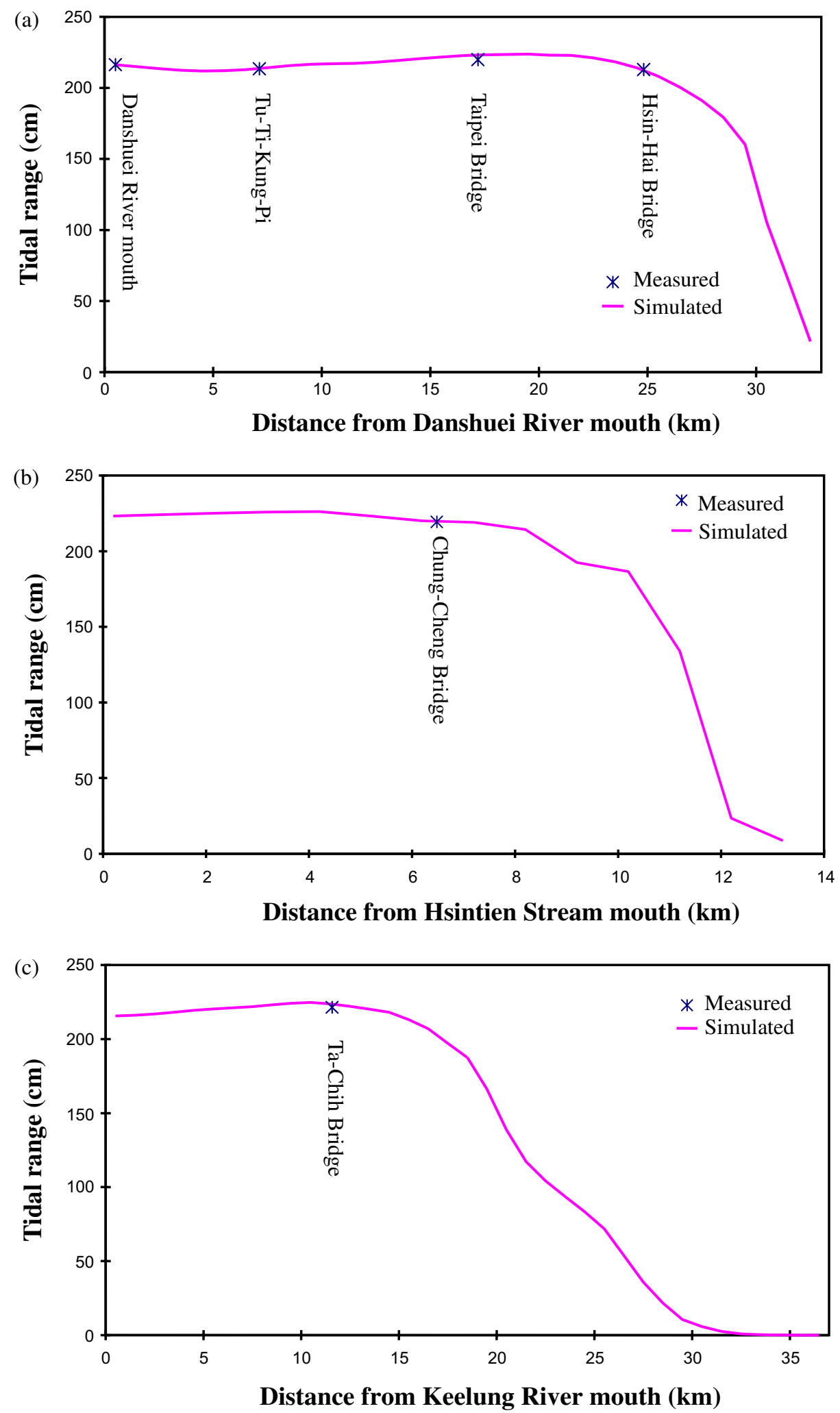

Fig. 2. Mean tide simulation results of (a) Danshuei River-Tahan Stream, (b) Hsintien Stream, and (c) Keelung River.

Eq. (7) can be directly applied to calculate residence time if $M$, the total mass of the tracer remaining in the system, decreases monotonically as time proceeds, that is, the time differential of $M$ remains negative. In estuaries, the forcing of river discharges and astronomic tides will ultimately flush the introduced substances out of the system if there is no further source. River discharges and ebb tides push/draw the tracer out of 


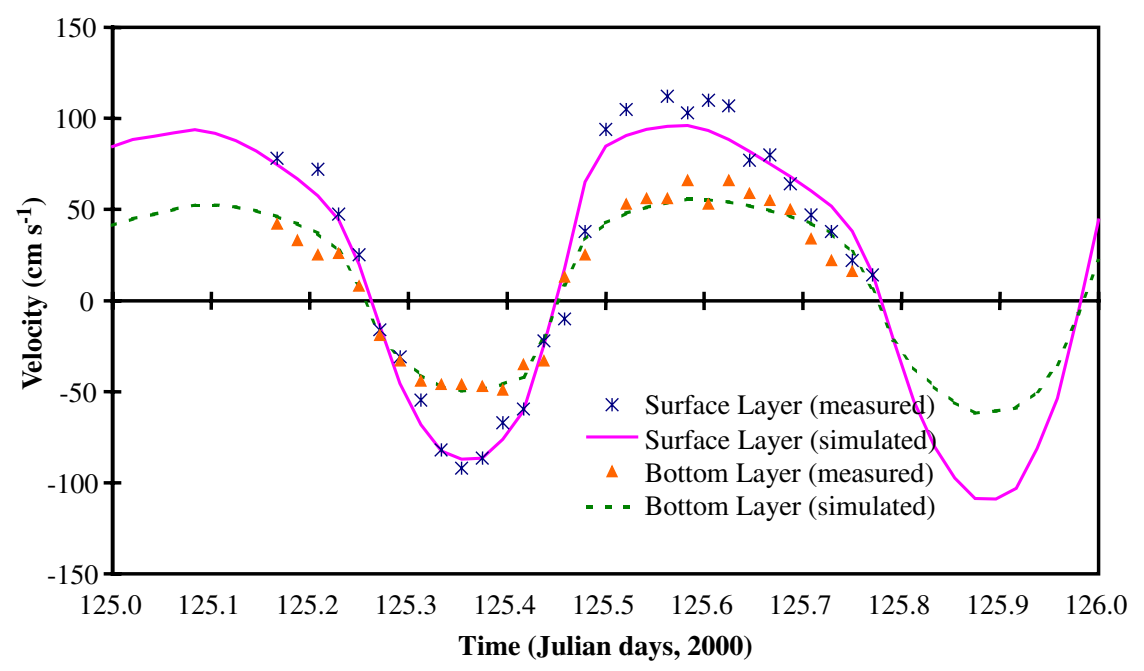

Fig. 3. Simulated velocities compared with observation at Kuan-Du Bridge on May 5, 2000.

the estuaries while flood tides, on the contrary, return portion of the tracer which was flushed out during the preceding ebb. As a consequence, the residual mass may increase and result in positive time differential during part of flood tide that invalidates Eq. (7). This occurs because the tracer concentration at river mouth does not drop to zero immediately at the beginning of flood tide. It is allowed to decrease linearly from the concentration at the end of ebb tide to zero over a specified period that is shorter than the duration of flood. This specified period is determined to be $3 \mathrm{~h}$ through the examination of the intra-tidal salinity variation at the Danshuei River mouth and model calibration with respect to salinity distribution in the river.

Fig. 4 demonstrates an example of the simulation results under the scenario of median river discharges with $\mathrm{M}_{2}$ tide and sea water salinity at the river mouth. It presents the temporal variations of the total volume of the water body and the residual mass of the tracer remaining in the Danshuei River. Total water volume decreases on ebb tide while increases on flood tide and appears in a regular pattern corresponding to the specified tidal period. At certain moment while the volume reaches the maximum, tracer is instantly released uniformly (point a in Fig. 4). On the following ebb tide, residual mass decreases as the water volume gradually declines (points a to b). After the volume reaches the minimum, flood tide carries back portion of the tracer that left the system on the previous ebb through river mouth, thus the residual mass increases (points $b$ to $c$ ). As flood tide proceeds upstream some tracer is pushed upriver into the tributaries, and lost from

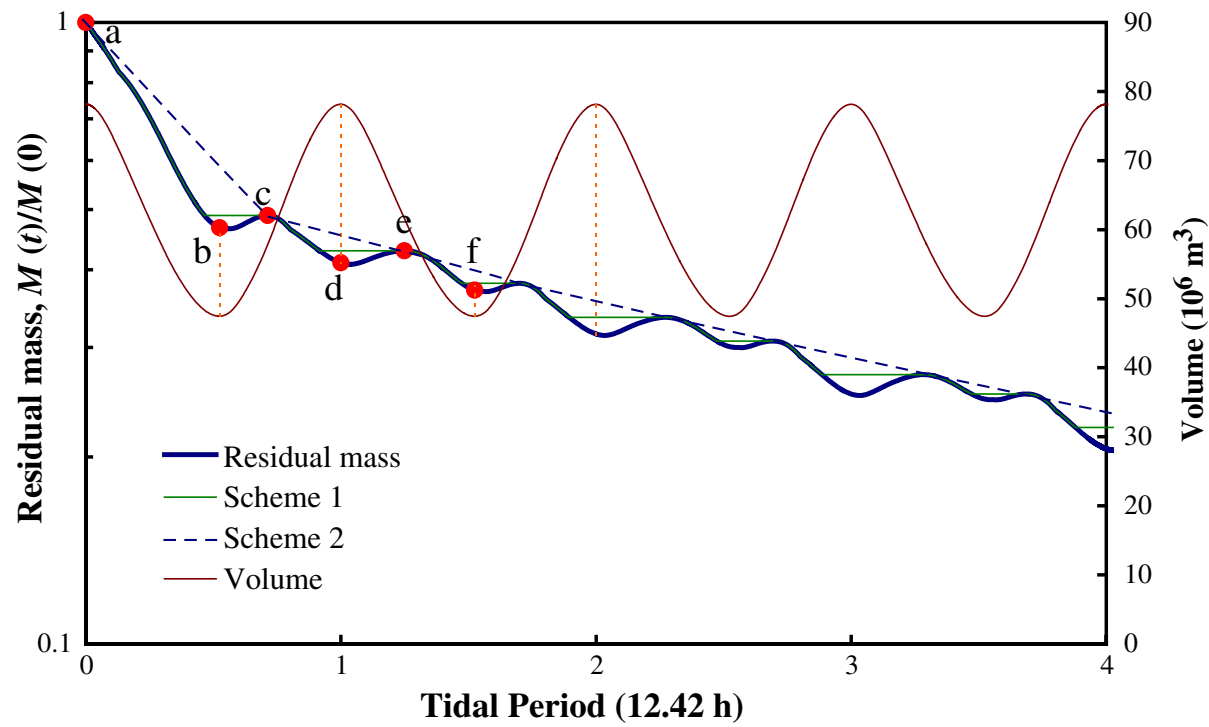

Fig. 4. The simulation results of total water volume and residual mass of tracer in the Danshuei River under the median river discharges with $\mathrm{M}_{2}$ tide and salinity intrusion at the river mouth. 
the region of interest. Once the flux of tracer to the tributaries exceeds that returning from the sea with flood water, the residual mass ceases increasing and reaches the second tentative maximum (point c). Afterward the residual mass begins to decrease for the remaining periods of flood tide as more tracer is pushed upriver (points $\mathrm{c}$ to d). One tidal period after the tracer is initially introduced, total water volume reaches maximum again, and the second tentative minimum of residual mass is reached (point d). Subsequently ebb tide commences. Some tracer is flushed out by ebb flow through river mouth while those in the tributaries may return to the Danshuei River. The residual mass exhibits slight increase prior to decreasing on the ebb tide (points d to e to f). The flux through river mouth is smaller on the early stage of ebb and increases as ebb flow becomes stronger. It eventually becomes larger than the mass flux from the tributaries, and the residual mass decreases. When the minimum volume is reached again, the residual mass reaches its third tentative minimum (point $\mathrm{f}$ ). With the alternate flood and ebb tides and continuous river discharges, the aforementioned processes occur repeatedly and eventually flush all tracer out of the Danshuei River.

Since Eq. (7) is not applicable for the time period the residual mass is increasing with time, the $M(t)$ curve (Fig. 4) needs to be adjusted before residence time may be computed. The increases in residual mass at the early stages of each flood and ebb cycle represent the return of portion of the tracer which left the area of interest earlier. Therefore that portion of the tracer should not be considered as being flushed out at the first place. The concave part of the $M(t)$ curve should be replaced with a horizontal line extending backward from each maximum of the curve (scheme 1 of Fig. 4). An alternate simplified scheme is to approximate the residual mass curve by connecting all the maxima of the curve (scheme
2 of Fig. 4). Scheme 2 would result in a longer residence time than that of scheme 1 . The overestimate diminishes as the amount of the returning mass decreases, or the relative forcing of the flood tide weakens. A sensitivity test shows that the difference between the two schemes is $2.4 \mathrm{~h}$ when the forcing of the flood tide is the strongest, i.e., zero river discharge. The difference decreases to $1.7 \mathrm{~h}$ at the mean river discharge. This is small compared to the calculated residence time, usually in days, thus the simplified scheme (scheme 2) is adopted herein.

One issue remains in the application of Eq. (7) is the upper limit of the integration. Theoretically, the integration should proceed to the time when the residual mass reaches zero. In most circumstances, this may take infinitely long time. Another sensitivity test is conducted by taking the limit of integration to various amount of residual mass. Fig. 5 shows the calculated residence time as function of upper limit of integration. According to the sensitivity test results, $0.1 \%$ of residual mass is designated to be the upper limit of the integration in Eq. (7) in this study.

In this study, the model is run to conduct tracer flushing experiments not only to calculate the residence time but also to investigate the relative contributions to the flushing by each of the three major physical transport mechanisms: tide, river discharge, and the density induced circulation. A series of numerical model simulations are executed. The scenarios are grouped into two categories:

Category A: Mechanisms including tide, river discharge, and density induced circulation.

Category B: Mechanisms including tide and river discharge.

The tidal forcing is specified with an $\mathrm{M}_{2}$ tide of the amplitude of $108 \mathrm{~cm}$ in all model runs. The contribution

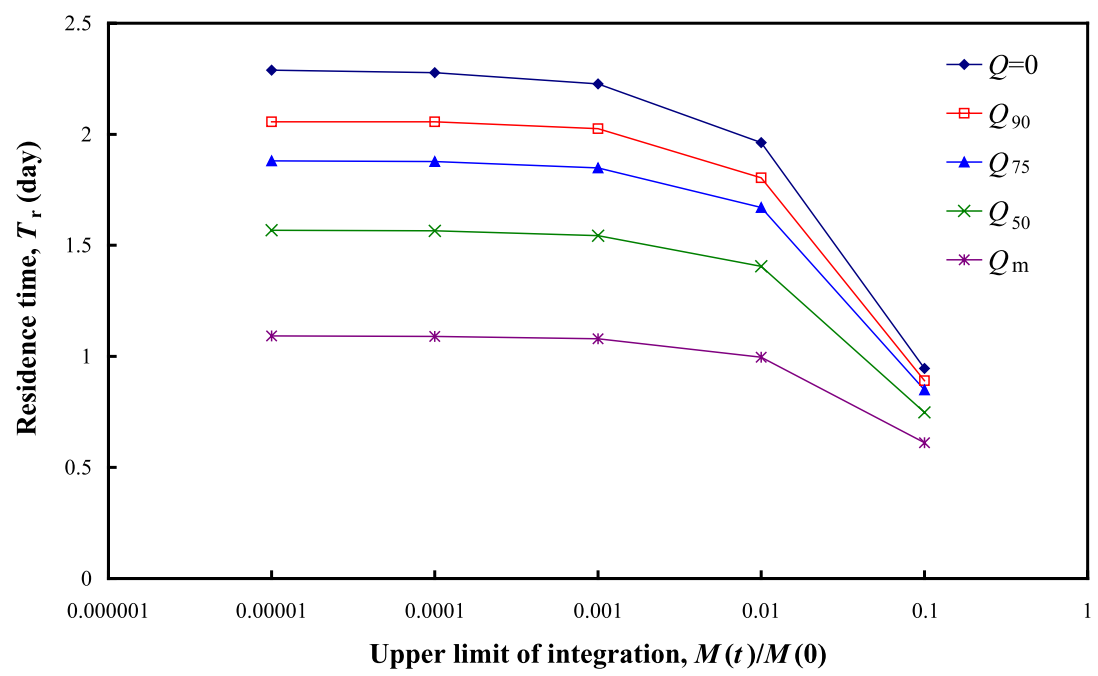

Fig. 5. Residence time as function of upper limit of integration in Eq. (7) $\left(Q=0\right.$ : zero flow discharge; $Q_{90}, Q_{75}$, and $Q_{50}$ : the flow that is equaled or exceeded 90,75 , and $50 \%$ of time, respectively; $Q_{\mathrm{m}}$ : mean flow discharge). 
Table 1

River discharges $\left(\mathrm{m}^{3} \mathrm{~s}^{-1}\right)$ at upstream boundaries for various scenarios of model simulations

\begin{tabular}{lccc}
\hline & Tahan Stream & Hsintien Stream & Keelung River \\
\hline$Q=0$ & 0.0 & 0.0 & 0.0 \\
$Q_{90}$ & 2.2 & 7.0 & 1.2 \\
$Q_{75}$ & 4.0 & 12.0 & 3.5 \\
$Q_{50}$ & 12.8 & 23.8 & 9.8 \\
$Q_{\mathrm{m}}$ & 41.0 & 57.5 & 25.3 \\
\hline
\end{tabular}

by river discharge is investigated with a series of model runs in both categories. The river flows at the upstream boundaries are varied from zero to the long-term mean. Table 1 lists the river discharges at upstream boundaries used in the numerical experiments with mean flow $Q_{\mathrm{m}}$, $Q_{50}$ flow (the flow that is equaled or exceeded $50 \%$ of time), $Q_{75}$ flow and $Q_{90}$ flow. The particular scenario with no river discharge is also included. It represents the case only the tidal flushing is in effect.

For all scenario runs in Category A, the ocean salinity of 35 is specified for the downstream boundary condition, the high tide salinity at river mouth. This will simulate the salinity intrusion and result in some density gradient in the system. Liu et al. (2001c) have shown that the density induced circulation is strong enough at some parts of the system that a two-layered density circulation may exist. For all scenario runs in Category $\mathrm{B}$, zero salinity is specified for the downstream boundary condition, thus the model simulations do not include density circulation. The differences between the corresponding scenarios in Categories A and B represent the contribution of the density induced circulation.

Table 2 lists the results of residence time of the Danshuei River under various scenarios. The scenarios in Category A stand for the realistic conditions that exist in prototype. The Danshuei River empties into the Taiwan Strait in which the salinity is about 35. The calculated residence times range from 1 to 2 days under various river discharge conditions. In both Categories A and $\mathrm{B}$, the residence time decreases with increasing river discharges. The results with and without salinity are essentially identical implying that there is no contribution from the density induced circulation to the flushing of this estuary. This seems contrary to the finding by Liu et al. (2001c) that there is strong two-layered residual circulation in some parts of the Danshuei River estuary. The two-layered circulation exists only if the baroclinic forcing is strong enough to overcome the barotropic forcing. This requires strong longitudinal salinity gradient as well as deep enough water depth. It turns out that the deepest part of the river, $12 \mathrm{~m}$, is located around Kuan-Du Bridge (Fig. 1), where the salinity gradient is strong and, thus, the two-layered circulation persists. In the lowest $5 \mathrm{~km}$ reach of the river, the channel depth is $7 \mathrm{~m}$ or less, thus the baroclinic forcing is weak. The tidal average (residual) velocity at river mouth is in seaward direction at all depth. There is no net inflow from the adjacent sea to enhance the flushing of the estuary.

Since the flushing abilities attributable to various physical transport mechanisms are cumulative while their corresponding residence times are not, it is necessary to quantify the flushing abilities in order to segregate the contributions to flushing by each of the mechanisms. The flushing rate is defined as the reciprocal of residence time and also listed in Table 2. Subtracting the flushing rate of Category B from that of Category A under the same river flow condition, the difference is the contribution from density induced circulation. They are minute in all cases and may be regarded as the numerical computation errors. As discussed earlier, it indicates that the density induced circulation has little contribution to the flushing process in the Danshuei River. The case of zero river discharge in Category B represents the tidal flushing alone, having a flushing rate of $0.45 \mathrm{~d}^{-1}$. The contribution of river discharge is then derived by subtracting the contribution of tide from the other cases in Category B. As expected, the flushing rate increases with river discharges. Under the $Q_{\mathrm{m}}$ flow, the river discharge contributes about the same amount of flushing as the tide.

Table 2

The results of corresponding time scales by the numerical model scenario runs, modified tidal prism method, and the fraction of freshwater method

\begin{tabular}{|c|c|c|c|c|c|c|c|c|c|c|}
\hline \multirow{3}{*}{$\begin{array}{l}\text { River } \\
\text { discharge }\end{array}$} & \multicolumn{6}{|c|}{ Numerical model with Eq. (7) } & \multicolumn{3}{|c|}{ Modified tidal prism method } & \multirow{2}{*}{$\begin{array}{l}\text { Fraction } \\
\text { of } \\
\text { freshwater } \\
\text { method }\end{array}$} \\
\hline & Category A & Category B & Category A & Category B & Contribution & Contribution & Eq. (A3) & Eq. (A4) & & \\
\hline & $\begin{array}{l}\text { Residence } \\
\text { time } T_{\mathrm{r}} \\
\text { (d) }\end{array}$ & $\begin{array}{l}\text { Residence } \\
\text { time } T_{\mathrm{r}} \\
\text { (d) }\end{array}$ & $\begin{array}{l}\text { Flushing } \\
\text { rate } T_{\mathrm{r}}^{-1} \\
\left(\mathrm{~d}^{-1}\right)\end{array}$ & $\begin{array}{l}\text { Flushing } \\
\text { rate } T_{\mathrm{r}}^{-1} \\
\left(\mathrm{~d}^{-1}\right)\end{array}$ & $\left(d^{-1}\right)$ & $\left(d^{-1}\right)$ & $\begin{array}{l}\text { Residence } \\
\text { time } T_{\mathrm{r}} \\
\text { (d) }\end{array}$ & $\begin{array}{l}\text { Residence } \\
\text { time } T_{\mathrm{r}} \\
\text { (d) }\end{array}$ & $\begin{array}{l}\frac{(\mathrm{A} 3)-(7)}{(7)} \\
(\%)\end{array}$ & $\begin{array}{l}\text { Flushing } \\
\text { time } T_{\mathrm{f}} \\
\text { (d) }\end{array}$ \\
\hline$Q=0$ & 2.23 & 2.23 & 0.449 & 0.448 & 0.001 & - & $2.23^{\mathrm{a}}$ & $2.23^{\mathrm{a}}$ & - & - \\
\hline$Q_{90}$ & 2.02 & 2.02 & 0.494 & 0.495 & -0.001 & 0.047 & 2.14 & 2.19 & 5.8 & 4.02 \\
\hline$Q_{75}$ & 1.85 & 1.85 & 0.541 & 0.541 & 0.000 & 0.093 & 2.07 & 2.16 & 12.0 & 3.65 \\
\hline$Q_{50}$ & 1.54 & 1.55 & 0.648 & 0.646 & 0.002 & 0.198 & 1.87 & 2.07 & 21.4 & 3.06 \\
\hline$Q_{\mathrm{m}}$ & 1.08 & 1.08 & 0.926 & 0.926 & 0.000 & 0.478 & 1.48 & 1.86 & 37.4 & 2.10 \\
\hline
\end{tabular}

${ }^{\text {a }}$ The value is used to calibrate the return flow factor, $b$. 


\section{Discussion}

The use of Eq. (7) to compute the residence time of an estuary represents the direct application of its definition, i.e., actually computing the average of the time periods that all the water parcels reside in the estuary. Many alternative, indirect methods have been proposed to calculate the residence time (or flushing time, exchange time, etc. see Appendix A). In the following, some alternative methods will be applied, using the data generated by the numerical model simulations described in the previous section.

The simplest method to calculate flushing time is the tidal prism method. Applying Eq. (1) to the Danshuei River, it is obtained that the flushing time is 1.3 days regardless of the river discharge. The invariant flushing time under various river flows is foreseeable since the tidal flushing is the only transport mechanism accounted for in this method. Both the high and low tide volumes increase slightly when there is more river discharge coming from upriver, but the tidal prism remains relatively constant. The increment in high and low tide volumes from zero river discharge to the $Q_{\mathrm{m}}$ flow is merely $1.4 \%$, resulting in little difference in the calculated flushing time. Under zero river discharge condition, the resulting flushing time is shorter than the corresponding residence time calculated by Eq. (7). It is attributed to the assumptions of complete mixing and no return flow in the tidal prism method. In the particular sensitivity run which assumes zero return flow in the model simulation, a residence time of 1.7 days is obtained from Eq. (7), which is still longer than the flushing time calculated by the tidal prism method. This difference is foreseeable since the Danshuei River is actually a partially mixed estuary.

It has been stated that the tidal prism method grossly underestimates the flushing time (Dyer, 1973). This is true only under the low flow condition when comparing the resulting flushing time with the residence times obtained by Eq. (7). At higher river flow, e.g., $Q_{\mathrm{m}}$, the tidal prism method gives a longer flushing time. This paradox is attributed to the definition that it only accounts for the transport mechanism of tide. The flushing by river discharge is not included in the calculation. The average time that a substance remains in the system is bound to shorten as the river discharge increases. In case the contribution of river discharge is comparatively significant relative to the tide, the residence time is likely to be shorter than that calculated by the tidal prism method. Both Sanford et al. (1992) and Luketina (1998) proposed modifications to the tidal prism method by including the contribution of river discharge as well as the return flow (Eqs. (A3) and (A4)). Applying the equations to the case of no river discharge, the return flow factor, $b$, is calculated to be 0.53 and 0.41 for Eqs. (A3) and (A4), respectively. Then the equations may be used to calculate the residence times for the various river discharge conditions. The results are compared with those calculated by Eq. (7) in Table 2. The discrepancy widens as river discharge increases.

The fraction of freshwater method (Eqs. (2) and (3)) has also been used often to calculate the flushing time. Most text books, however, leave it vague as referring to at which phase of tide the spatial distribution of salinity should be used in Eq. (3). Table 2 also lists the calculated flushing times by the fraction of freshwater method using the salinity at high tide when the Danshuei River has the maximum volume. The zero river discharge condition is not included since Eq. (2) becomes indeterminate. The flushing times are much longer than the residence times calculated with tracer flushing simulation and Eq. (7). This may be attributed to the difference in definitions. The flushing time in the fraction of freshwater method is defined as the time required to replace entire existing freshwater in the system once while the residence time is the average time the water resides in the system. If the saline water in the system is also replaced at the same rate as the freshwater, then the residence time equals the time required to replace half of the water in the system. It is interesting to note that the fraction of freshwater method yields flushing times about twice the residence times obtained by Eq. (7) (Table 2).

Asselin and Spaulding (1993) applied various data sets and methodologies, including the fraction of freshwater method, to calculate the flushing time of the Providence River. The study area is $20-\mathrm{km}$ long and with a volume of $88 \times 10^{6} \mathrm{~m}^{3}$ which is similar to the Danshuei River, 21$\mathrm{km}$ long with a volume of $63 \times 10^{6} \mathrm{~m}^{3}$ below mean sea level. The average flushing time in the Providence River was estimated to be 2.5 days for the mean freshwater inflow of $42.3 \mathrm{~m}^{3} \mathrm{~s}^{-1}$. Fig. 6 shows the empirical relationship derived by Asselin and Spaulding (1993) for the flushing time of the Providence River and that derived from the present study for the flushing time of the Danshuei River. The flushing time of the Providence River is more sensitive to the variation in freshwater inflows than the Danshuei River. Providence River is a tributary of Narragansett Bay, not directly discharges into the open sea as the Danshuei River does. It has a tidal range of $1.22 \mathrm{~m}$ at the mouth while the Danshuei River has a much larger tidal range of $2.17 \mathrm{~m}$. Therefore the relative contribution of river discharge to the flushing is more important in the Providence River.

\section{Conclusions}

The residence time of the Danshuei River and the contributions by each of the three major physical transport mechanisms are investigated through a series of numerical experiments. The results show that the residence time is relatively short, ranging from about two 


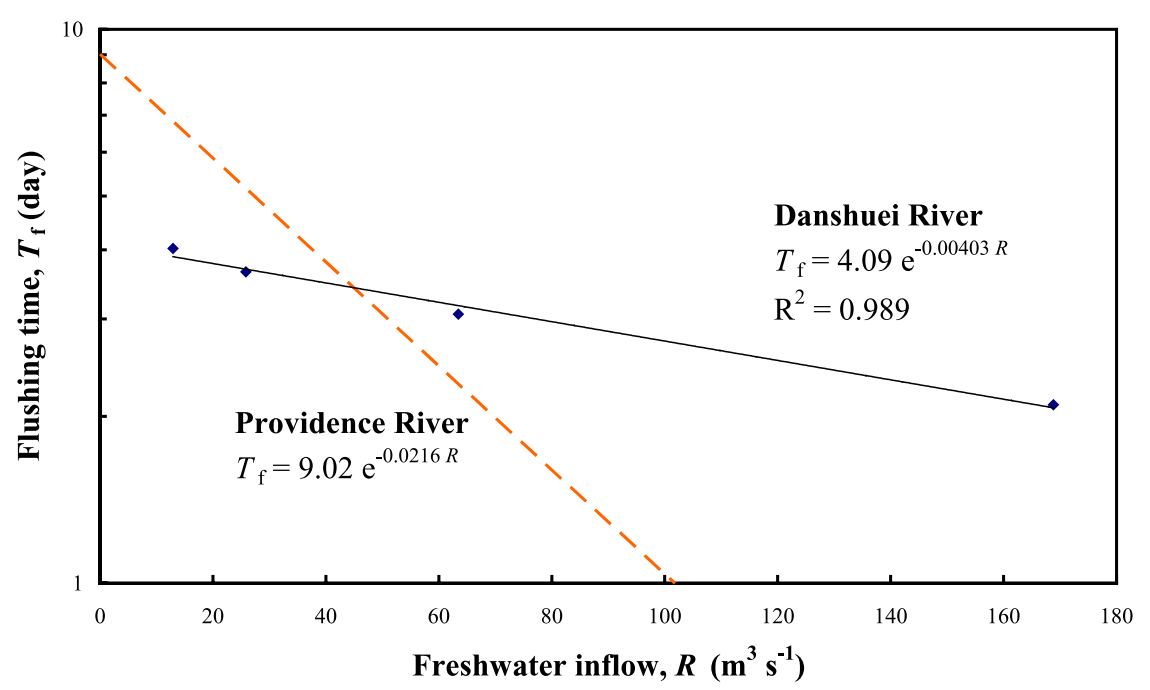

Fig. 6. Comparison of the flushing time between Providence River and the Danshuei River (dots: results of the Danshuei River by the fraction of freshwater method under specified river discharges; solid line: regression of dots; dash line: results obtained by Asselin and Spaulding (1993)).

days at zero river discharge to one day at the mean river flow condition. In general conditions, tidal flushing exerts great influence on the transport process while the density induced circulation hardly contributes any in this estuary. No upriver residual flow develops in the shallower outer part of the estuary, even though the two-layered estuarine circulation exists in the deeper part of the estuary. Tidal transport contributes more than $50 \%$ of the flushing when river discharge is below its long-term mean.

The suitability of applying the tidal prism method and the fraction of freshwater method to the Danshuei River is also investigated. The original tidal prism method results in an invariant flushing time for its failure to account for the transport by the river discharge. Hence it is more suitable for estuaries with the river discharge negligible compared to tidal prism. Both the refinements by Sanford et al. (1992) and Luketina (1998) account for the river discharge as well as the flood tide return flow, assuming that they are independent. Both methods give the residence times decreasing with increasing river discharge. They agree reasonably well with those calculated by Eq. (7), though they are consistently higher. The flushing times estimated using the fraction of freshwater method are approximately two times the residence times obtained by Eq. (7). This is consistent with their respective definitions.

The relative short residence time is likely to be one of the limiting factors that result in low phytoplankton biomass in the Danshuei River estuary. Similar observations have been reported in many other estuaries around the world. For example, Monbet (1992) conducted a comparative analysis of data from 40 estuaries of various tidal ranges. He found that mean annual chlorophyll levels are significantly lower in systems with high tidal ranges even though nitrogen concentrations were equal to nitrogen levels in the microtidal systems. $\mathrm{He}$ attributed the lower productivity in the macrotidal systems to the stronger tidal mixing, higher sediment resuspension and lower light penetration. In the light of the conclusion drawn in this study, Monbet's conclusion may also be interpreted as the shorter residence time in macrotidal systems. Balls et al. (1995) investigated the long-term nutrient enrichment in a macrotidal estuary in Scotland. They reported that the approximately fourfold increase in nitrogen loading did not appear to have a significant increase in chlorophyll concentration. They attributed this observation to the relatively short flushing period of the estuary. Boston Harbor is another example; Kelly (1997) attributed to its short residence time (strong tidal flushing) for the low nitrogen concentration and small phytoplankton standing crops in the harbor in spite of its high nitrogen loading. He estimated that about $90 \%$ of the nitrogen loading was exported to shallow shelf waters of Massachusetts Bay, where it strongly influenced the ecological dynamics.

On the other hand, a short residence time is beneficial to pollutant removal. Because of the excessive pollutant loadings, water quality remains poor throughout the Danshuei River estuary in spite of the short residence time. A significant fraction of pollutants is exported and exerts their effects in the coastal waters outside the estuary.

\section{Acknowledgements}

The project under which this study was conducted is supported by National Science Council, Taiwan, grant numbers NSC 91-2211-E-002-067. The field data for numerical model calibration/verification are provided by Taiwan Water Resources Agency. 


\section{Appendix A. Terminology of time scales}

Various terms have been used in the literatures as the integral time scale quantifying the gross effect of physical transport processes in estuaries. They are closely related even though they are not exactly the same because of their respective definitions and underlying assumptions. Different investigators may use the same term with different definitions and/or assumptions, while some may use different terms for the same definition. This appendix summarizes the most commonly used terms, their definitions or the ways to calculate them, and the references where they appeared.

\section{A.1. Flushing time}

1. The time required to replace the existing freshwater in the whole or a segment of the estuary at a rate equal to river discharge:

$T_{\mathrm{f}}=\frac{V_{\mathrm{f}}}{R} \quad$ Bowden (1967), Dyer (1973),

Officer (1976), Fischer et al. (1979)

2. The volume of sea water and river water introduced on the flood tide equals the tidal prism, and the same volume of water is removed on the ebb tide:

$T_{\mathrm{f}}=\frac{(V+P) T}{P} \quad$ Bowden (1967), Dyer (1973)

\section{A.2. Residence time}

1. The time required for the total mass of a conservative tracer originally within the whole or a segment of the estuary to be reduced to a factor of $\mathrm{e}^{-1}$ (i.e., 0.37), Modification of A.1 (Point 2),

$T_{\mathrm{r}}=\frac{(V+P / 2) T}{(1-b) P+R T} \quad$ Sanford et al. (1992)

$T_{\mathrm{r}}=\frac{(V+P) T}{(1-b) P+R T / 2} \quad$ Luketina $(1998)$

2. The time required for a particle to travel from a location to the boundary of the region (Prandle, 1984), therefore it is dependent of the location where the particle is released. van de Kreeke (1983) further differentiated the phase of tide when the particle was initially released.

3. The average time for all existing water in the whole or a segment of the estuary to remain in the original domain, defined in this paper:

$$
T_{\mathrm{r}}=\frac{1}{M(0)} \int_{0}^{\infty} t\left[-\frac{\mathrm{d} M(t)}{\mathrm{d} t}\right] \mathrm{d} t
$$

\section{A.3. Renewal time}

The time required to replace a specified fraction of the water in an estuary by the volume flows of freshwater and new ocean salt water (Pritchard, 1960), e.g., the $50 \%$ renewal time:

$T_{1 / 2}=0.693 \frac{V}{R+Q}$

Pritchard equated mean renewal time to mean residence time:

$T_{\mathrm{m}}=\frac{V}{R+Q}$

\section{A.4. Mean detention time}

The mean time that a particle of tracer remains inside an estuary, also termed flushing time, see A.1 (Point 1), Fischer et al. (1979).

\section{A.5. Turn-over time}

1. Similar to A.1 (Point 1), Bolin and Rodhe (1973).

2. Same as A.2 (Point 1), Prandle (1984).

\section{A.6. Exchange time}

Same as A.2 (Point 1), Gillibrand (2001).

\section{A.7. Transit time}

The period between the times a particle entering and leaving an estuary, Bolin and Rodhe (1973).

\section{A.8. Age}

The time that has elapsed since the water parcel enters an estuary, Bolin and Rodhe (1973).

$b: \quad$ return flow factor

$f$ : $\quad$ fraction of fresh water

$V$ : low tide volume of the whole or a segment of the estuary

$V_{\mathrm{f}}$ : volume of freshwater accumulated in the whole or a segment of the estuary

$R: \quad$ river discharge

$P: \quad$ tidal prism 
$Q$ : $\quad$ salt water flow rate, or volume of new water coming into the estuary on flood tide

$T:$ tidal period

\section{References}

Asselin, S., Spaulding, M.L., 1993. Flushing times for the Providence River based on tracer experiments. Estuaries 16 (4), 830-839.

Balls, P.W., Macdonald, A., Pugh, K., Edwards, A.C., 1995. Longterm nutrient enrichment of an estuarine system: Ythan, Scotland (1958-1993). Environmental Pollution 90 (3), 311-321.

Bolin, B., Rodhe, H., 1973. A note on the concepts of age distribution and transit time in natural reservoirs. Tellus 25, 58-62.

Bowden, K.F., 1967. Circulation and diffusion. In: Lauff, G.H. (Ed.), Estuaries, American Association for Advancement of Science, Publication No. 83, Washington, D.C., pp. 15-36.

Cerco, C., Cole, T., 1993. Three-dimensional eutrophication model of Chesapeake Bay. ASCE Journal of Environmental Engineering 119 (6), 1006-1025.

Chen, S.Y., Wu, C.R., Hsu, M.H., Liu, W.C., Kuo, A.Y., 2003. Water column light attenuation in the Danshuei River estuary, Taiwan. Abstracts, Pacific Congress of Marine Science and Technology, Nov. 30-Dec. 3, 2003, Kaohsiung, Taiwan, p. 138.

Chen, Y.C., Hung, T.C., 1988. The behavior and mobilization of trace metals in the Danshuei River. Journal of the Environmental Protection Society of the Republic of China 11, 21-31, (in Chinese).

Dettmann, E., 2001. Effect of water residence time on annual export and denitrification of nutrient in estuaries: a model analysis. Estuaries 24 (4), 481-490.

Dyer, K.R., 1973. Estuaries: A Physical Introduction. John Wiley \& Sons, New York, 140 pp.

Dyer, K.R., 2000. Estuaries: A Physical Introduction, second ed. John Wiley \& Sons, New York, 195 pp.

Dyer, K.R., Taylor, P.A., 1973. A simple, segmented prism model of tidal mixing in well-mixed estuaries. Estuarine and Coastal Marine Science 1, 411-448.

Edinger, J.E., Buchak, E.M., Kolluru, V.S., 1998. Modeling flushing and mixing in a deep estuary. Water, Air, and Soil Pollution 102, $345-353$.

Fischer, H.B., List, E.J., Koh, R.C.Y., Imberger, J., Brooks, N.H., 1979. Mixing in Inland and Coastal Waters. Academic Press, New York, 483 pp.

Gillibrand, P.A., 2001. Calculating exchange times in a Scottish fjord using a two-dimensional, laterally-integrated numerical model. Estuarine, Coastal and Shelf Science 53, 437-449.

Howarth, R.W., Swaney, D.P., Butler, T.J., Marino, R., 2000. Climatic control on eutrophication of the Hudson River estuary. Ecosystems 3, 210-215.

Hsu, M.H., Kuo, A.Y., Kuo, J.T., Liu, W.C.,1996, 1997. Study of tidal characteristics, estuarine circulation and salinity distribution in Tanshui River system (I) \& (II), Technical Report No. 239, Hydrotech Research Institute, National Taiwan University, Taipei, Taiwan, 245 pp. (in Chinese).

Hsu, M.H., Kuo, A.Y., Kuo, J.T., Liu, W.C., 1999. Procedure to calibrate and verify numerical models of estuarine hydrodynamics. ASCE Journal of Hydraulic Engineering 125, 166-182.

Jay, D.A., Uncle, R.J., Largier, J., Geyer, W.R., Vallino, J., Boynton, W.R., 1997. A review of recent development in estuarine scalar flux estimation. Estuaries 20, 262-280.
Kelly, J.R., 1997. Nitrogen flow and the interaction of Boston Harbor with Massachusetts Bay. Estuaries 20 (2), 365-380.

Ketchum, B.H., 1951. The exchanges of fresh and salt water in tidal estuaries. Journal of Marine Research 10, 18-38.

Kim, S.C., Kuo, A.Y., Kuon, J., 2002. A model study of flushing characteristics of the Elizabeth River, Virginia. In: Spaulding, M.L., Blumberg, A.M. (Eds.), Estuarine and Coastal Modeling, ASCE Proceedings of the 7th International Conference, Reston, VA.

Knauss, J.A., 1978. Introduction to Physical Oceanography. PrenticeHall, Englewood Cliff, N.J., 338 pp.

Kuo, A.Y., Neilson, B.J., 1988. A modified tidal prism model for water quality in small coastal embayments. Water Science and Technology 20 (6/7), 133-142.

Liu, W.C., Hsu, M.H., Kuo, A.Y., Kuo, J.T., 2001a. The influence of river discharge on salinity intrusion in the Tanshui estuary, Taiwan. Journal of Coastal Research 17 (3), 544-552.

Liu, W.C., Hsu, M.H., Kuo, A.Y., Li, M.H., 2001b. Influence of bathymetric changes on hydrodynamics and salt intrusion in estuarine system. Journal of American Water Resources Association 37 (5), 1405-1416.

Liu, W.C., Hsu, M.H., Kuo, A.Y., 2001c. Investigation of long-term transport in Tanshui Estuary, Taiwan. Journal of Waterway, Port, Coastal and Ocean Engineering 127 (2), 61-71.

Luketina, D., 1998. Simple tidal prism model revisited. Estuarine, Coastal and Shelf Science 46, 77-84.

Monbet, Y., 1992. Control of phytoplankton biomass in estuaries: a comparative analysis of microtidal and macrotidal estuaries. Estuaries 15 (4), 563-571.

Monsen, N.E., Cloern, J.E., Lucas, L.V., 2002. A comment on the use of flushing time, residence time, and age as transport time scales. Limnology and Oceanography 47 (5), 1545-1553.

Officer, C.B., 1976. Physical Oceanography of Estuaries (and Associated Coastal Waters). Wiley, New York, 465 pp.

Park, K., Kuo, A.Y., Neilson, B.J., 1996. A numerical model study of hypoxia in the tidal Rappahannock River of Chesapeake Bay. Estuarine, Coastal and Shelf Science 42, 453-581.

Prandle, D.A., 1984. A modeling study of the mixing of 137Cs in the sea of the European continental shelf. Philosophical Transaction of the Royal Society of London 310, 407-436.

Pritchard, D.W., 1960. Salt balance and exchange rate for Chincoteague Bay. Chesapeake Science 1, 48-57.

Pritchard, D.W., 1969. Dispersion and flushing of pollutants in estuaries. ASCE Journal of Hydraulics Division 95 (HY1), $115-124$

Rasmussen, B., Josefson, A.B., 2002. Consistent estimates for the residence time of micro-tidal estuaries. Estuarine, Coastal and Shelf Science 54, 65-73.

Sanford, L.P., Boicourt, W.C., Rives, S.R., 1992. Model for estimating tidal flushing of small embayments. ASCE Journal of Waterway, Port, Coastal and Ocean Engineering 118 (6), 635-654.

Sheldon, J.E., Alber, M., 2002. A comparison of residence time calculations using simple compartment models of the Altamaha River estuary, Georgia. Estuaries 25 (6B), 1304-1317.

van de Kreeke, J., 1983. Residence time: application to small boat basins. ASCE Journal of Waterway, Port, Coastal and Ocean Engineering 109 (4), 416-428.

Wood, T., 1979. A modification of existing simple segmented tidal prism models of mixing in estuaries. Estuarine and Coastal Marine Science 8, 339-347.

Zimmerman, J.T.F., 1988. Estuarine residence times. In: Kjerfve, B. (Ed.), Hydrodynamics of Estuaries 1, Estuarine Physics. CRC Press, Inc., Boca Raton, Florida, pp. 76-84. 